\section{The Differentiation of Chilling Requirements of Kiwifruit Cultivars Related to Ploidy Variation}

\author{
Tingting Zhao and Dawei Li
}

Key Laboratory of Plant Germplasm Enhancement and Specialty Agriculture, Wuhan Botanical Garden, Chinese Academy of Sciences, Wuhan, Hubei 430074, People's Republic of China

\section{Lulu Li}

Key Laboratory of Plant Germplasm Enhancement and Specialty Agriculture, Wuhan Botanical Garden, Chinese Academy of Sciences, Wuhan, Hubei 430074, People's Republic of China; and the University of Chinese Academy of Sciences, Beijing 100039, People's Republic of China

\section{Fei Han, Xiaoli Liu, Peng Zhang, Meiyan Chen, and Caihong Zhong ${ }^{\mathbf{1}}$ Key Laboratory of Plant Germplasm Enhancement and Specialty Agriculture, Wuhan Botanical Garden, Chinese Academy of Sciences, Wuhan, Hubei 430074, People's Republic of China}

Additional index words. chilling requirement, kiwifruit cultivars, ploidy level, correlation

\begin{abstract}
Kiwifruit (Actinidia chinensis Planchon) is an economically important fruit, and its flowering and production are affected by the chill accumulation in winter. In this study, the chilling requirements of nine kiwifruit cultivars with three ploidy levels (diploid, tetraploid, and hexaploid) were analyzed by using the Dynamic Model, Utah Model, and chilling hours (CH) Model. The chilling requirements for vegetative budbreak of these kiwifruit cultivars were $24-55$ chill portions (CP), 316-991 chill units (CU), and 222-853 $\mathrm{CH}$, and the chilling requirements for floral emergence were 45-69 $\mathrm{CP}, 825-1336 \mathrm{CU}$, and $655-1138 \mathrm{CH}$. The chilling requirements for vegetative budbreak and floral emergence were significantly lower for diploid than hexaploid cultivars with tetraploid cultivars intermediate. Pearson correlation analysis indicated that ploidy levels were positively correlated with chilling requirement, with the CV of 0.74 and 0.82 for vegetative budbreak and floral emergence chilling requirements, respectively. In conclusion, these results provide some novel insights of kiwifruit varieties of various chilling requirements, which is beneficial for kiwifruit cultivar selection for different climates and environments.
\end{abstract}

Dormancy is an adaptation of perennial plants to cease growth in response to extreme environmental conditions (Rohde and Bhalerao, 2007). Dormancy is induced by diverse factors in different plants (Vegis, 1964), whereas dormancy termination is usually influenced by chilling in winter (Fuchigami et al., 1982; Perry, 1971; Wareing, 1956). Temperature and duration of chilling are key components of satisfying chilling requirements which are critical to promote vegetative growth and budbreak for perennial plants in the subsequent year (Perry, 1971). Temperatures near $5{ }^{\circ} \mathrm{C}$ are required to satisfy the chilling requirement of perennial plants

Received for publication 16 May 2017. Accepted for publication 31 Oct. 2017.

This research is supported by MOA (2016NWB025), CAS (KFJ-EW-T-076), and NSFC (31570678) of China.

We thank Xiaohong Yao for his assistance in the preparation of the article.

${ }^{1}$ Corresponding author. E-mail: zhongch@ wbgcas.cn. natural Actinidia chinensis and Actinidia deliciosa from China (Ferguson and Huang, 2007). Compared with other fruit trees, limited information is available about the effects of temperature on the chilling requirement in the Actinidia genus. It has been reported that Actinidia rufa displayed a low-chill trait $(200 \mathrm{~h})$ followed by $A$. chinensis (400-600 h), and $A$. deliciosa cultivars showed the highest chilling requirements $(600-800 \mathrm{~h})$ (Kulthinee et al., 2004). In addition, there is an obvious variation of chilling requirements among various cultivars of an Actinidia species. For example, 'Hayward' (A. deliciosa) had a chilling requirement of more than $950 \mathrm{CU}$ for vegetative buds and $1150 \mathrm{CU}$ for floral buds, whereas 'Bruno' (A. deliciosa) may have lower chilling requirements (Caldwell, 1989). However, information has not been reported about the chilling requirements of other kiwifruit cultivars, especially for the new released cultivars with diverse ploidy levels.

Because of China's fluctuating climate and diverse environment (Luedeling, 2012), the appropriate chilling requirements of kiwifruit cultivars are essential for cultivar selection and cultivation. The objectives of this study were to 1) determine chilling requirements for vegetative budbreak and floral emergence of different kiwifruit cultivars and 2) investigate the relationship of chilling requirements with different ploidy levels.

\section{Materials and Methods}

Plant material. The plant material used in this study comprised nine kiwifruit cultivars with three ploidy levels including the diploids 'Jinyu' (originate from Henan province), 'Donghong' (Henan), and 'Wuzhi-7' (Jiangxi); the tetraploids 'Jintao' (Jiangxi), 'Jinxia' (Jiangxi), and ' $\mathrm{H}-15$ ' (Hunan); and the hexaploids 'Jinkui' (Hubei), 'Chuanmi-1' (Sichuan), and 'Bruno' (New Zealand). The ploidies of these cultivars have been determined by flow cytometry experiments (Huang, 2014). The former five cultivars belong to Actinidia chinensis, and the remaining cultivars belong to Actinidia deliciosa. All these kiwifruit cultivars were cultivated at the National Actinidia Germplasm Repository (NAGR) at the Wuhan Botanical Garden, Chinese Academy of Science.

Experimental design. The experiments were conducted in 2014 and 2015 in the NAGR orchard. Hourly temperatures were collected from September to March by an electronic thermohygrograph (Zoglab Model DSR-TH; Zoglab, Hangzhou, China). The starting date for chilling accumulation was considered when "positive chill-units begin to accumulate just after the day in the autumn when the largest negative accumulation is experienced" (Erez et al., 1979; Richardson et al., 1974). For the Utah Model, the largest negative accumulation of $\mathrm{CU}$ was detected on 2 Nov. (data not shown), hence we began calculating CU on 3 Nov. For the Dynamic Model and $\mathrm{CH}$ Model, we began calculating $\mathrm{CP}$ and $\mathrm{CH}$ on 1 Sept., respectively (Zhang 
Table 1. Chill accumulation under field conditions in Wuhan, China (2014-15), according to the dynamic model, Utah model, and chilling hours (CH) model.

\begin{tabular}{|c|c|c|c|c|c|c|c|c|c|c|}
\hline Model & 1 Nov. & 3 Nov. & 15 Nov. & 30 Nov. & 15 Dec. & 31 Dec. & 15 Jan. & 31 Jan. & $15 \mathrm{Feb}$ & $28 \mathrm{Feb}$. \\
\hline Portions (dynamic model) & 0 & 1 & 6 & 13 & 24 & 35 & 44 & 55 & 61 & 67 \\
\hline Chill units (Utah model) & - & 10.5 & 70.0 & 193.5 & 408.5 & 603.5 & 784.5 & 963.5 & $1,049.0$ & $1,143.5$ \\
\hline $\mathrm{CH}$ (CH model) & 0 & 7 & 23 & 45 & 242 & 436 & 614 & 828 & 965 & 965 \\
\hline
\end{tabular}

and Taylor, 2011). For each kiwifruit cultivar, 30 canes (lengths: $30-40 \mathrm{~cm}$, diameter: $5 \mathrm{~mm}$ ) with about five buds were collected on 15 Dec., 29 Dec., 6 Jan., 23 Jan., and 8 Feb., respectively. These 30 canes were then evenly spaced in a greenhouse in triplicate at $22{ }^{\circ} \mathrm{C}$ with natural sunlight and $65 \%$ relative humidity and maintained for several weeks. Shoot counts that emerged from buds were recorded daily. Floral buds were also counted, as well as the stage of development of each flower, including full bloom, petal fall, and senescence. Once a bud developed into a shoot with flowers, it was regarded as a floral bud. Data were collected until leaves appeared chlorotic or necrotic and floral parts stopped developing or had abscised (Wall et al., 2008).

Determination of chilling requirements. The percentages of vegetative budbreak and floral emergence were calculated out of total buds and were used as indicators of chilling requirement. The chilling requirement for each kiwifruit cultivar was estimated using regression analysis which was performed based on the percentages of vegetative budbreak and floral emergence and the chilling accumulation. The optimal regression equation with the highest regression coefficient was selected for further analysis. The percentages of vegetative budbreak and floral emergence reaching 50\% indicate the fulfillment of chill requirement for budbreak and flower, respectively (Zhang and Taylor, 2011). Thus, the chill requirements for vegetative budbreak and floral emergence were estimated to be the CP (Dynamic Model), CU (Utah Model), and $\mathrm{CH}$ (CH Model) when the percentages of vegetative budbreak and floral emergence were equal to $50 \%$, respectively.

Statistical analysis. Statistical analysis was performed using SPSS ${ }^{\circledR}$ Statistics V21 (Chicago, IL). All data are reported as mean values with standard deviations. Differences among diploid, tetraploid, and hexaploid were tested by using one-factor analysis of variance (ANOVA). When ANOVA was significant, the means were discriminated using the Tukey's test for the post hoc pairwise comparisons. The correlation between chilling requirement and ploidy levels was estimated by the use of the Pearson correlation coefficient.

\section{Results}

Chilling accumulation under field conditions. The chilling accumulation between 1 Sept. and $28 \mathrm{Feb}$. was measured by ' $\mathrm{CP}$ ', 'CU', and ' $\mathrm{CH}$ ' (Table 1). The results of the three models all revealed that positive chilling accumulation began on 3 Nov. December and January were the two most efficient months in relation to chill accumulation. In all, more than $60 \mathrm{CP}, 1000$ $\mathrm{CU}$, and $900 \mathrm{CH}$ of chill accumulation were

Table 2. The percentages of vegetative budbreak and floral emergence for canes with different chilling accumulations in nine kiwifruit cultivars.

\begin{tabular}{|c|c|c|c|c|c|c|c|c|c|c|c|}
\hline \multirow[b]{2}{*}{ Cultivars } & \multirow[b]{2}{*}{ Ploidy } & \multicolumn{5}{|c|}{ Vegetative budbreak (\%) } & \multicolumn{5}{|c|}{ Floral emergence $(\%)$} \\
\hline & & $24^{z}$ & 33 & 38 & 48 & 59 & 24 & 33 & 38 & 48 & 59 \\
\hline Jinyu & $2 x$ & $16 \mathrm{a}$ & $43 \mathrm{~b}$ & $54 \mathrm{ce}$ & 71 be & $62 \mathrm{ab}$ & $7 \mathrm{~b}$ & $24 \mathrm{e}$ & $41 \mathrm{e}$ & $44 \mathrm{~b}$ & $55 \mathrm{~b}$ \\
\hline Donghong & $2 x$ & $54 \mathrm{e}$ & $57 \mathrm{e}$ & $62 \mathrm{e}$ & $86 \mathrm{e}$ & $90 \mathrm{e}$ & $29 \mathrm{~d}$ & $30 \mathrm{f}$ & $38 \mathrm{e}$ & $57 \mathrm{c}$ & $69 \mathrm{c}$ \\
\hline Wuzhi-7 & $2 x$ & $34 \mathrm{~d}$ & $37 \mathrm{ab}$ & $43 \mathrm{~b}$ & $70 \mathrm{~b}$ & $69 \mathrm{~b}$ & $5 \mathrm{~b}$ & $19 \mathrm{~d}$ & $21 \mathrm{c}$ & $38 \mathrm{ab}$ & $51 \mathrm{ab}$ \\
\hline Jintao & $4 x$ & $16 \mathrm{a}$ & $26 \mathrm{a}$ & $38 \mathrm{ab}$ & $52 \mathrm{a}$ & $54 \mathrm{a}$ & $8 \mathrm{~b}$ & $21 \mathrm{de}$ & $28 \mathrm{~d}$ & $44 \mathrm{~b}$ & $45 \mathrm{ab}$ \\
\hline Jinxia & $4 x$ & $22 \mathrm{ab}$ & $29 \mathrm{a}$ & $47 \mathrm{bc}$ & $63 \mathrm{~b}$ & $64 \mathrm{ab}$ & $15 \mathrm{c}$ & $23 \mathrm{de}$ & $26 \mathrm{~cd}$ & $43 \mathrm{~b}$ & $54 \mathrm{~b}$ \\
\hline H-15 & $4 x$ & $29 \mathrm{bcd}$ & $32 \mathrm{a}$ & $40 \mathrm{ab}$ & $41 \mathrm{a}$ & $55 \mathrm{a}$ & $8 \mathrm{~b}$ & $20 \mathrm{de}$ & $22 \mathrm{~cd}$ & $33 \mathrm{ab}$ & $48 \mathrm{ab}$ \\
\hline Jinkui & $6 x$ & $16 \mathrm{a}$ & $27 \mathrm{a}$ & $42 \mathrm{ab}$ & $48 \mathrm{a}$ & $50 \mathrm{a}$ & $0 \mathrm{a}$ & $0 \mathrm{a}$ & $3 a$ & $36 \mathrm{ab}$ & $37 \mathrm{a}$ \\
\hline Chunmi-1 & $6 x$ & $25 \mathrm{bc}$ & $29 a$ & $32 \mathrm{a}$ & $50 \mathrm{a}$ & $57 \mathrm{ab}$ & $7 \mathrm{~b}$ & $10 \mathrm{~b}$ & $12 \mathrm{~b}$ & $27 \mathrm{a}$ & $43 \mathrm{ab}$ \\
\hline Bruno & $6 x$ & $31 \mathrm{~cd}$ & $34 \mathrm{ab}$ & $37 \mathrm{ab}$ & $48 \mathrm{a}$ & $63 \mathrm{ab}$ & $5 \mathrm{~b}$ & $15 \mathrm{c}$ & $20 \mathrm{c}$ & $31 \mathrm{ab}$ & $48 \mathrm{ab}$ \\
\hline
\end{tabular}

Means followed by different letters in the same column differ significantly at $5 \%$ of the Tukey's multiple range tests.

${ }^{\mathrm{z}}$ The chill accumulation for treated canes in the field conditions according to the dynamic model.

Table 3. Chilling requirements for vegetative budbreak and floral emergence in nine kiwifruit cultivars.

\begin{tabular}{|c|c|c|c|c|c|c|}
\hline \multirow[b]{2}{*}{ Cultivars } & \multicolumn{3}{|c|}{$\begin{array}{l}\text { Chilling requirements for } \\
\text { vegetative budbreak }^{z}\end{array}$} & \multicolumn{3}{|c|}{$\begin{array}{l}\text { Chilling requirements for } \\
\text { floral emergence }\end{array}$} \\
\hline & Portions & $\mathrm{CU}$ & $\mathrm{CH}$ & Portions & $\mathrm{CU}$ & $\mathrm{CH}$ \\
\hline Jinyu & $42 \mathrm{~b}$ & $693 \mathrm{ab}$ & $572 \mathrm{~b}$ & $53 \mathrm{ac}$ & $961 \mathrm{ab}$ & $820 \mathrm{ab}$ \\
\hline Donghong & $24 \mathrm{a}$ & $316 \mathrm{a}$ & $222 \mathrm{a}$ & $45 \mathrm{a}$ & $825 \mathrm{a}$ & $655 \mathrm{a}$ \\
\hline Wuzhi-7 & $40 \mathrm{~b}$ & $673 \mathrm{ab}$ & $543 \mathrm{~b}$ & $59 \mathrm{ad}$ & $1,086 \mathrm{ab}$ & $908 \mathrm{ab}$ \\
\hline Jintao & $52 \mathrm{bc}$ & $962 \mathrm{~b}$ & $776 \mathrm{bc}$ & $60 \mathrm{bcd}$ & $1,110 \mathrm{ab}$ & $1,013 \mathrm{~b}$ \\
\hline Jinxia & $44 \mathrm{bc}$ & $728 \mathrm{~b}$ & $617 \mathrm{bc}$ & $58 \mathrm{ab}$ & $1,027 \mathrm{ab}$ & $925 \mathrm{ab}$ \\
\hline H-15 & $55 \mathrm{c}$ & $991 \mathrm{~b}$ & $832 \mathrm{c}$ & $63 \mathrm{bcd}$ & $1,179 \mathrm{ab}$ & $961 \mathrm{~b}$ \\
\hline Jinkui & $54 \mathrm{c}$ & $961 \mathrm{~b}$ & $853 \mathrm{c}$ & $67 \mathrm{bcd}$ & $1,262 \mathrm{~b}$ & $1,041 \mathrm{~b}$ \\
\hline Chunmi-1 & $52 \mathrm{bc}$ & $913 \mathrm{~b}$ & $769 \mathrm{bc}$ & 69 bd & $1,336 \mathrm{~b}$ & $1,138 \mathrm{~b}$ \\
\hline Bruno & $49 \mathrm{bc}$ & $956 \mathrm{~b}$ & 746 bc & $63 \mathrm{bcd}$ & $1,202 \mathrm{~b}$ & $956 \mathrm{ab}$ \\
\hline
\end{tabular}

Means followed by different letters in the same column differ significantly at $5 \%$ of the Tukey's multiple range tests.

${ }^{\mathrm{z}}$ The chilling requirements represent the chilling accumulation for $50 \%$ vegetative budbreak and floral emergence.

$\mathrm{CH}=$ chilling hours; $\mathrm{CU}=$ chill units.

Table 4. Association analysis of ploidy levels with chilling requirements in kiwifruit.

\begin{tabular}{|c|c|c|c|c|c|c|}
\hline \multirow[b]{2}{*}{ Ploidy level } & \multicolumn{3}{|c|}{$\begin{array}{l}\text { Chilling requirements } \\
\text { for vegetative budbreak }\end{array}$} & \multicolumn{3}{|c|}{$\begin{array}{l}\text { Chilling requirements } \\
\text { for floral emergence }\end{array}$} \\
\hline & Portions & $\mathrm{CU}$ & $\mathrm{CH}$ & Portions & $\mathrm{CU}$ & $\mathrm{CH}$ \\
\hline Diploid & $35 \pm 9 a$ & $560 \pm 212 a$ & $446 \pm 194 \mathrm{a}$ & $52 \pm 7 \mathrm{a}$ & $957 \pm 130 \mathrm{a}$ & $794 \pm 128 \mathrm{a}$ \\
\hline Tetraploid & $50 \pm 5 \mathrm{ab}$ & $894 \pm 144 a b$ & $742 \pm 111 \mathrm{ab}$ & $60 \pm 2 a b$ & $1,105 \pm 76 \mathrm{ab}$ & $966 \pm 44 \mathrm{ab}$ \\
\hline Hexaploid & $52 \pm 2 b$ & $943 \pm 26 b$ & $789 \pm 56 b$ & $66 \pm 3 b$ & $1,267 \pm 67 b$ & $1,045 \pm 91 \mathrm{~b}$ \\
\hline
\end{tabular}

Means followed by different letters in the same column differ significantly at $5 \%$ of the Tukey's multiple range tests.

${ }^{\mathrm{z}}$ The chilling requirements represent the chilling accumulation for $50 \%$ vegetative budbreak and floral emergence.

$\mathrm{CH}=$ chilling hours; $\mathrm{CU}=$ chill units .

detected until 28 Feb. in Wuhan, which was cold enough to study the chilling requirement of kiwifruit.

Chilling requirements for vegetative budbreak and floral emergence. The chilling accumulations until 15 Dec., 29 Dec., 6 Jan., 23 Jan., and 8 Feb. were calculated to be 24 , $33,38,48$, and $59 \mathrm{CP}$ for the Dynamic Model; 271, 581.5, 679, 869, and 1025 CU for the Utah Model; and 242, 406, 500, 711, and $927 \mathrm{CH}$ for the $\mathrm{CH}$ Model, respectively. In most cases, the percentages of vegetativebudbreak and floral emergence gradually increased for the canes with increased chilling accumulations (Table 2). The chill requirements representing the chill accumulations for $50 \%$ vegetative budbreak and floral emergence were shown in Table 3. The chilling requirements for vegetative budbreak and floral emergence of the nine kiwifruit cultivars were 24-55 CP (316-991 $\mathrm{CU}$ or 222-853 $\mathrm{CH})$ and 45-69 CP (825$1336 \mathrm{CU}$ or $655-1138 \mathrm{CH}$ ), with the lowest values in 'Donghong'. At the chilling accumulation of $24 \mathrm{CP}$ (271 CU or $242 \mathrm{CH})$, the percentages of vegetative budbreak and floral emergence in 'Donghong' were significantly higher than that of other cultivars (Fig. 1). Within the tetraploid or hexaploid cultivars, there was no significant difference of chill 
requirement between any pairs of cultivars. However, within diploid cultivars, 'Donghong' showed significantly lower chilling requirement for budbreak than 'Jinyu' and 'Wuzhi-7'. For all cultivars, the chilling requirements for vegetative budbreak were lower than that for floral emergence.

Correlation between chilling requirements and ploidy levels. The average values of chilling requirements for vegetative budbreak and floral emergence in diploid cultivars were 35 and 52 CP (560 and 957 CU or 446 and 794 $\mathrm{CH}$ ), respectively, which were both significantly lower than those in hexaploid cultivars (Table 4). The average correlation coefficients
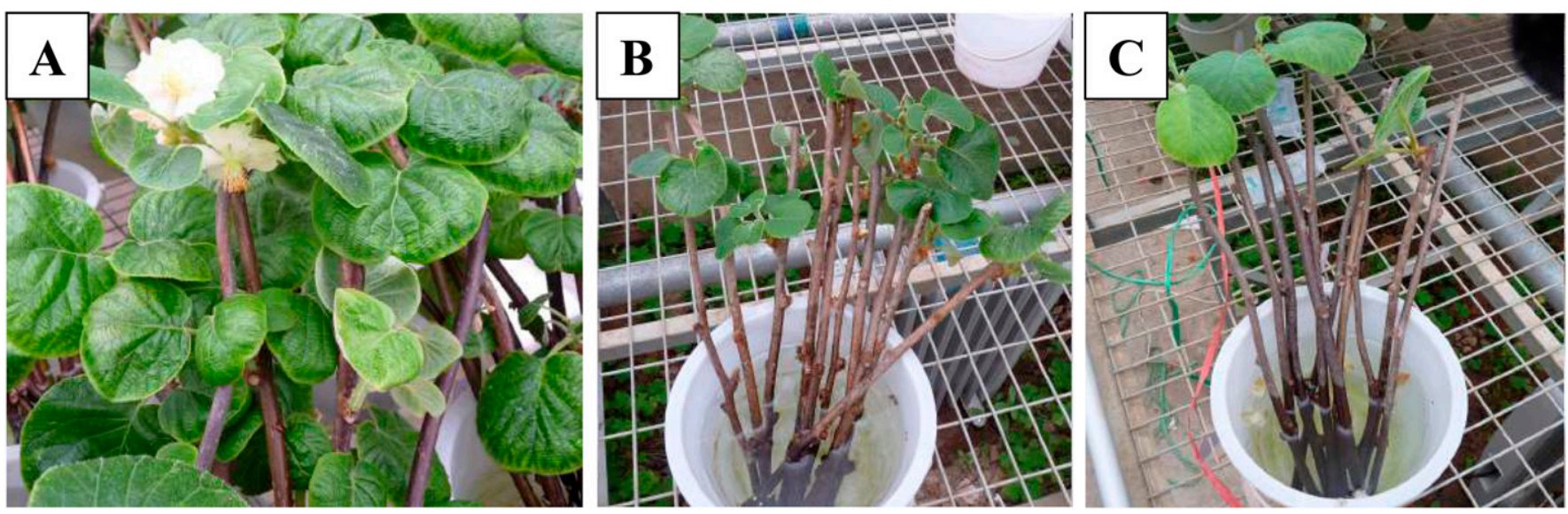

Fig. 1. The vegetative budbreak and floral emergence of three different kiwifruit cultivars with different ploidy levels at 24 chill portions, which corresponded to 271 chill units and 242 chilling hours. (A) Diploid cv. Donghong; (B) Tetraploid cv. H-15; (C) Hexaploid cv. Jinkui.

(A)

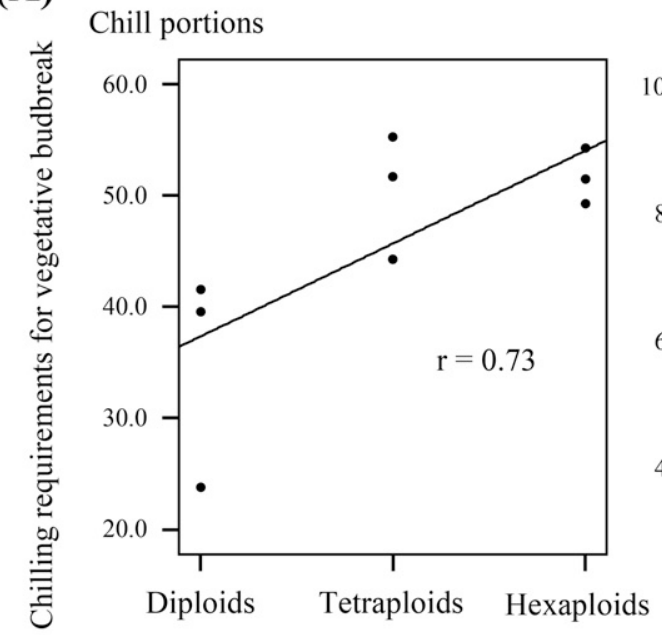

(B)

Chill portions

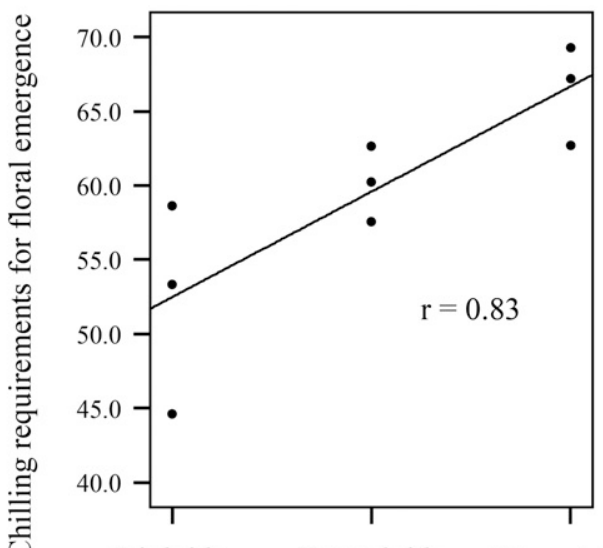

Diploids Tetraploids Hexaploids
Chill units

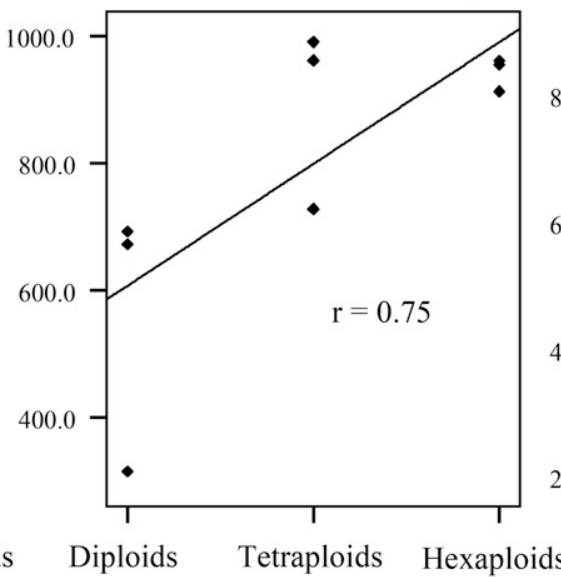

Chilling hours

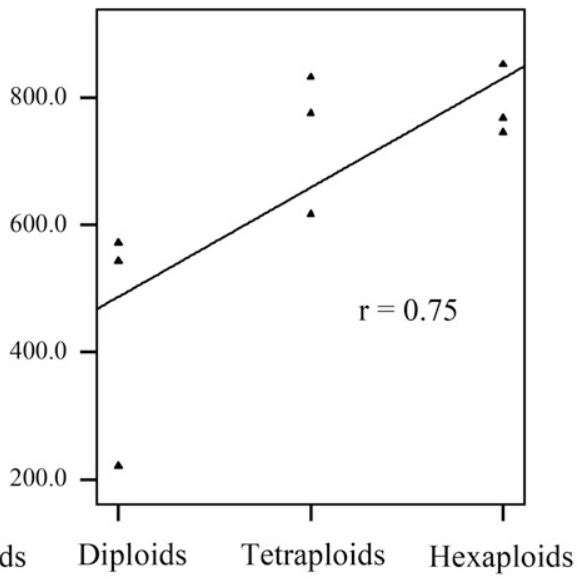

\section{Chill units}

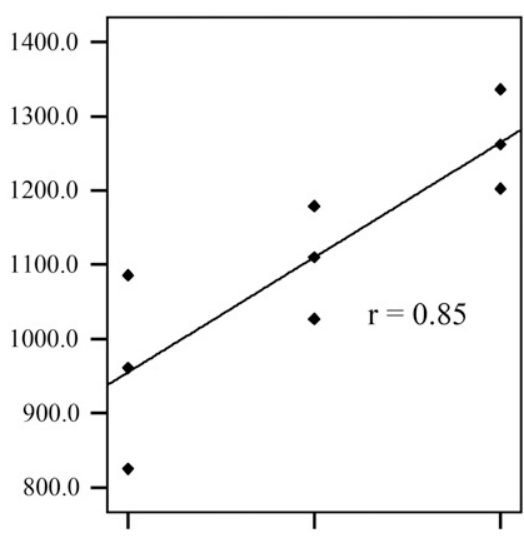

Diploids Tetraploids Hexaploids
Chilling hours

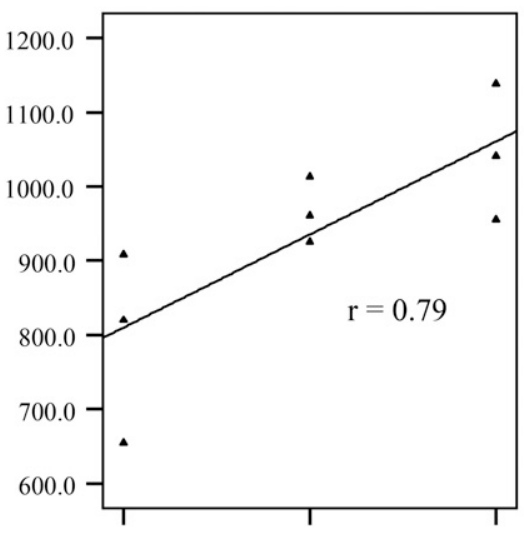

Diploids Tetraploids Hexaploids

Fig. 2. The relationship of ploidy with chilling requirements for vegetative budbreak (A) and floral emergence (B). Significance of the regression coefficient was determined at $P<0.05$. Each data point represents the mean value of a cultivar. 
between ploidy levels and chilling requirements for vegetative budbreak and floral emergence across all models were 0.74 and 0.82 , respectively (Fig. 2), indicating that both vegetative budbreak and floral emergence were positively related to the ploidy levels.

\section{Discussion}

In our field conditions, the correlation coefficient between portions (Dynamic model) and CU (Utah model) was higher than that between portions and $\mathrm{CH}(\mathrm{CH}$ model) and between $\mathrm{CU}$ and $\mathrm{CH}$ (data not shown). Similarly, in estimating chilling requirements, the correlation between the Dynamic and Utah models $(r=0.99)$ is very high, which is similar to that reported in previous studies (Erez and Fishman, 1998; Ruiz et al., 2007). Hence, both the Dynamic and Utah models are suitable for estimating chilling requirements for kiwifruit cultivars in Wuhan. The correlations between the $\mathrm{CH}$ and Dynamic models $(r=0.97)$ were also quite high, as well as between the $\mathrm{CH}$ and Utah models $(r=0.95)$, indicating that the $\mathrm{CH}$ model could be a useful and reasonable method for growers.

The chilling requirement studies provide basic information for cultivation management and plant selection for specific sites (Dennis, 2003; Faust et al., 1991). In this study, the chilling requirements were estimated for kiwifruit cultivars with different ploidy levels. 'Donghong' showed the lowest chilling requirements and the highest break percentages for vegetative budbreak and floral emergence, revealing that it may be the most suitable cultivar for adaptation to warmer climates. Within the diploid level, considerable differences in chilling requirement were observed (Table 3), which indicates that selecting lower chilling or higher chilling materials is possible by interspecific or intraspecific hybrids. The chilling requirements of hexaploid cultivars were significantly higher than those of diploid cultivars, indicating hexaploids need higher chilling accumulation in winter than the diploids. Interploidy and intraspecific hybridization may be useful breeding strategies to improve the chilling requirement for specific growing zones. For example, Kataoka et al. (2014) selected selections below $300 \mathrm{CH}$ by intraspecific hybridization of $A$. chinensis and $A$. rufa.

\section{Conclusions}

The kiwifruit cultivars examined in this study showed a wide range of chilling requirements for vegetative budbreak from 24 to $55 \mathrm{CP}, 316$ to $991 \mathrm{CU}$, and 222 to $853 \mathrm{CH}$. Floral emergence had higher chilling requirements than vegetative budbreak. A significant difference in chilling requirement was observed among the cultivars within the diploid level. The chilling requirements for vegetative budbreak and floral emergence in diploid cultivars were significantly lower than those in hexaploid cultivars with tetraploid cultivars intermediate. Significant correlations were determined between the ploidy levels and chilling requirements for vegetative budbreak and floral emergence. Our results provide baseline data for the breeding, selection, cultivation, and management of kiwifruit.

\section{Literature Cited}

Alburquerque, N., F. García-Montiel, A. Carrillo, and L. Burgos. 2008. Chilling and heat requirements of sweet cherry cultivars and the relationship between altitude and the probability of satisfying the chill requirements. Environ. Expt. Bot. 64:162-170.

Brundell, D. 1975. Flower development of the Chinese gooseberry (Actinidia chinensis Planch.) II. Development of the flower bud. N. Z. J. Bot. 13:485-496.

Caldwell, R. 1989. Kiwifruit performance in South Carolina and effect of winter chilling. Clemson University, Clemson, SC.

Dennis, F.G. 2003. Problems in standardizing methods for evaluating the chilling requirements for the breaking of dormancy in buds of woody plants. HortScience 38:347-350.

Egea, J., E. Ortega, P. Martıìnez-Gómez, and F. Dicenta. 2003. Chilling and heat requirements of almond cultivars for flowering. Environ. Expt. Bot. 50:79-85.

Erez, A., G.A. Couvillon, and C.H. Hendershott. 1979. The effect of cycle length on chilling negation by high temperatures in dormant peach leaf buds. J. Amer. Soc. Hort. Sci. 104:573-576.

Erez, A. and S. Fishman. 1998. The dynamic model for chilling evaluation in peach buds. Acta Hort. 465:507-510.

Faust, M., D. Liu, M.M. Millard, and G. Stutte. 1991. Bound versus free water in dormant apple buds: A theory for endodormancy. HortScience 26:887-890.

Ferguson, A.R. and H. Huang. 2007. Genetic resources of kiwifruit: Domestication and breeding. Hort. Rev. 33:1-121.
Fuchigami, L.H., C.J. Weiser, K. Kobayashi, R. Timmis, and L.V. Gusta. 1982. A degree growth stage $\left({ }^{\circ} \mathrm{GS}\right)$ model and cold acclimation in temperate woody plants, p. 93-116. In: P.H. Li and A. Sakai (eds.). Plant cold hardiness and freezing stress. Academic Press, New York, NY.

Huang, H. 2014. The genus Actinidia, a world monograph. Science Press, Beijing, China.

Huang, H.W., J.J. Gong, S.M. Wang, Z.C. He, Z.H. Zhang, and J.Q. Li. 2000. Genetic diversity in the genus Actinidia. Chinese Biodivers. 8:1-12.

Kataoka, I., H. Matsumoto, A. Kawano, K. Beppu, M. Ohtani, and K. Suezawa. 2014. Selection of low-chill kiwifruit adapting to warm climate by utilizing Actinidia Rufa native to southwestern part of Japan. Acta Hort. 1059:85-88.

Kulthinee, P., B. Kenji, M. Ryosuke, F. Tetsuo, and K. Ikuo. 2004. Low-chill trait for endodormancy completion in Actinidia arguta Planch. (Sarunashi) and A. rufa Planch. (Shimasarunashi), indigenous Actinidia species in Japan and their interspecific hybrids. J. Jpn. Soc. Hort. Sci. 73:244-246.

Li, D., Y. Liu, C. Zhong, and H. Huang. 2010 Morphological and cytotype variation of wild kiwifruit (Actinidia chinensis complex) along an altitudinal and longitudinal gradient in centralwest China. Bot. J. Linn. Soc. 164:72-83.

Luedeling, E. 2012. Climate change impacts on winter chill for temperate fruit and nut production: A review. Scientia Hort. 144:218-229.

Naor, A., M. Flaishman, R. Stern, A. Moshe, and A. Erez. 2003. Temperature effects on dormancy completion of vegetative buds in apple. J. Amer. Soc. Hort. Sci. 128:636-641.

Perry, T.O. 1971. Dormancy of trees in winter. Science 171:29-36.

Richardson, E.A., S.D. Seeley, and D.R. Walker. 1974. A model for estimating the completion of rest for "Redhaven" and "Elberta" peach trees. HortScience 9:331-332.

Rohde, A. and R.P. Bhalerao. 2007. Plant dormancy in the perennial context. Trends Plant Sci. 12:217-223.

Ruiz, D., J.A. Campoy, and J. Egea. 2007. Chilling and heat requirements of apricot cultivars for flowering. Environ. Expt. Bot. 61:254-263.

Vegis, A. 1964. Dormancy in higher plants. Annu. Rev. Plant Physiol. 15:185-224.

Wall, C., W. Dozier, R.C. Ebel, B. Wilkins, F. Woods, and W. Foshee. 2008. Vegetative and floral chilling requirements of four new kiwi cultivars of Actinidia chinensis and A. deliciosa. HortScience 43:644-647.

Wareing, P.F. 1956. Photoperiodism in woody plants. Annu. Rev. Plant Physiol. 7:191-214.

Zhang, J. and C. Taylor. 2011. The dynamic model provides the best description of the chill process on 'Sirora' pistachio trees in Australia. HortScience 46:420-425. 